\title{
Cupcake Brownies Satoiomo (Cc-Browsa) CV Firici Group
}

\author{
Nurbaya Busthanul $^{1}$, Masyhur Syafiuddin ${ }^{2}$, Heliawati $^{3}$, Rasyidah Bakri ${ }^{4}$, Rima Rahmawati ${ }^{5}$, \\ Cindy Fatika Sunaryani ${ }^{6}$, Moh. Fiqry Rosaldi ${ }^{7}$ \\ 1,3,4,5,6,7 Program Studi Agribisnis Fakultas Pertanian Universitas Hasanuddin, Makassar \\ ${ }^{2}$ Program Studi Agroteknologi Fakultas Pertanian Universitas Hasanuddin, Makassar
}

Email: n.busthanu10963@gmail.com

\begin{abstract}
Abstrak
Satoimo (Colocasia esculenta var. antiquorum) atau biasa dikenal dengan talas jepang merupakan salah satu sumber pangan karbohidrat tak-biasa karena kaya akan hyaluronic acid (HA), suatu zat yang diproduksi alami dalam tubuh dan menghasilkan kolagen alami. Bahan pangan yang kaya energi, namun rendah karbohidrat ini juga dekenal sebagai anti-oksidan dan anti-aging. Selain itu dapat dibuat berbagai macam makanan yang lezat, namun belum banyak dalam bentuk brownies. Tujuan pendirian 'pra-starup' CV. FIRICI GROUP adalah untuk melakukan percoban produksi dan pemasaran cupcake brownies satoimo berbasis inovasi yang lezat dan bergizi, higienis, harga terjangkau, dan ekonomis sehingga dapat dikembangkan sebagai usaha (bisnis). Usaha yang dibentuk dan dikelola oleh tiga mahasiswa di bawah binaan para dosen pembimbing telah berproduksi dan hasilnya dipasarkan sesuai rencana (target); yakni minimal 450 box sebulan, dengan total target 5.400 unit. Dengan harga jual sebesar Rp7.000/box, maka diperoleh hasil penjualan sebesar Rp3.150.000/bulan. Sementara total modal awal yang dibutuhkan hanya sebesar Rp2.787.000 atau masing-masing Rp929.000 per orang. Hasil analisis ekonomi denga beberapa indicator, menunjukkan bahwa usaha CC-BROWSA yang diinisiasi oleh 'CV FIRICI GROUP' layak untuk dikembangkan di Makassar.
\end{abstract}

Kata kunci: cakebrownies, satoimo, talas jepang, pra-startup.

\section{PENDAHULUAN}

Latar Belakang. Satoimo (Colocasia esculenta var. antiquorum) atau biasa dikenal dengan talas jepang merupakan salah satu sumber pangan karbohidrat tak-biasa karena kaya akan hyaluronic acid (HA), suatu zat yang diproduksi alami dalam tubuh dan menghasilkan kolagen alami. Bahan pangan yang kaya energi, namun rendah karbohidrat ini juga dekenal sebagai anti-oksidan dan anti-aging. Selain itu dapat dibuat berbagai macam makanan yang lezat, namun belum banyak dalam bentuk brownies.

Tujuan dan Rencana Penanganan Masalah. Tujuan pendirian 'pra-starup' CV. FIRICI GROUP adalah untuk melakukan percoban produksi dan pemasaran cupcake brownies satoimo berbasis inovasi yang lezat dan bergizi, higienis, harga terjangkau, dan ekonomis sehingga dapat dikembangkan sebagai usaha (bisnis).

Tinjauan Pustaka. Secara konseptual produk adalah pemahaman subyektif dari produsen atas sesuatu yang bisa ditawarkan, sebagai usaha untuk mencapai tujuan organisasi melalui pemenuhan kebutuhan dan keinginan konsumen, sesuai dengan kompetensi dan kapasitas organisasi serta daya beli pasar (Tjiptono, 2002). Produk meliputi kualitas, keistimewaan, desain, gaya, keanakeragaman, bentuk, merek, kemasan, ukuran, pelayanan dan jaminan. Produk Ekonomi, Sosial dan Budaya 1008 
mempunyai wujud tertentu dan sifat-sifat fisik tertentu, disamping itu terdapat tenggang waktu antara saat diproduksinya suatu produk dengan saat dikonsumsinya produk tersebut oleh konsumen (Kasmir, 2010).

Talas Jepang juga mengandung serat yang baik untuk pencernaan, sehingga dapat menjadi bahan campuran pembuatan brownies, agar-agar, campuran es krim, biskuit dan sup. Modifikasi sebagai perubahan struktur molekul dari pati dapat dilakukan secara kimia, fisika maupun enzimatis (Subagio A, 2007).

Talas jepang memiliki rasa gatal disebabkan oleh adanya kristal kecil berbentuk jarum halus yang tersusun atas kalsium oksalat yang disebut raphide (Bradbury and Nixon, 1998). Namun dapat dihilangkan dengan pemanasan (Smith, 1997). Pemanasan dilakukan melalui penjemuran, pemasakan (Lee, 1999); perebusan, perendaman dalam air hangat, pemanggangan (Iwuoha dan Klau, 1994); dan pengeringan. Pemanasan menyebabkan ikatan ion antar karbon kalsium oksalat terputus dan bagian organik terdekomposisi sebelum titik leleh tercapai. Perendaman umbi dalam air hangat (38$48^{\circ} \mathrm{C}$ ) selama kurang dari 4 jam diklaim dapat menurunkan kadar komponen penyebab gatal tanpa menyebabkan gelatinisasi pati (Nur, 1986).

Produk kami bernama "CC-BROWSA (Cup Cake Brownies Satoimo)". Penggunaan kata CC dikarenakan brownies ini kemasannya berbentuk cup seperti cup cake dan penggunaan BROWSA dikarenakan ingin memadukan kata brownies dan satoimo. Kemasan cup ini dimaksudkan agar konsumen yang ingin mencoba rasa CC-BROWSA dapat mencoba 1 cup terlebih dahulu dan tidak akan mubadzir jika mereka nantinya kurang menyukai produk kami karena 1 cup sudah cukup, tidak terlalu banyak ataupun sedikit. Memiliki berat netto 100 gram per cup, warna dasar coklat dengan bentuk dimensi yang unik: dalam cup dengan diameter $\pm 6,5$ $\mathrm{cm}$ (Gambar 1). Jan dimasukkan ke dalam box atau kotak dengan ukuran \pm 9x9x10,5 cm (Gambar 2).

Produk kami yaitu brownies satoimo yang berbentuk padatan yang serupa dengan brownies lainnya tetapi produk kami menambahkan talas jepang pada bahan baku utama dari brownies itu sendiri. Adapun alat dan bahan yang dibutuhkan dalam proses pembuatan produk ini ditunjukkan pada Tabel 1.

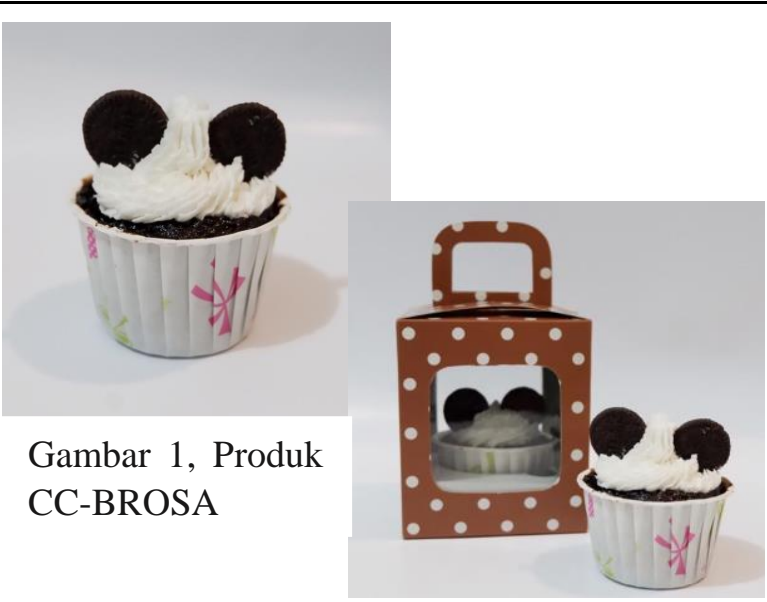

Gambar 2. Bentuk kemasan CC-BROSA

Label produk adalah bagian dan identitas produk. Menurut Tjiptono (2002), terdapat tiga macam yaitu (i) Brand Label, yaitu merek yang diberikan pada produk atau dicantumkan pada kemasan; (ii) Descriptive Label, yaitu label yang memberikan informasi objektif mengenai penggunaan, konstruksi atau pembuatan, perawatan atau perhatian dan kinerja produk serta karakteristik-karakterisrik lainnya yang berhubungan dengan produk; dan (iii) Grade Label, yaitu label yang mengidentifikasikan penilaian kualitas produk dengan huruf, angka atau kata. Untuk Browsa diperlihatkan dengan Gambar 3.

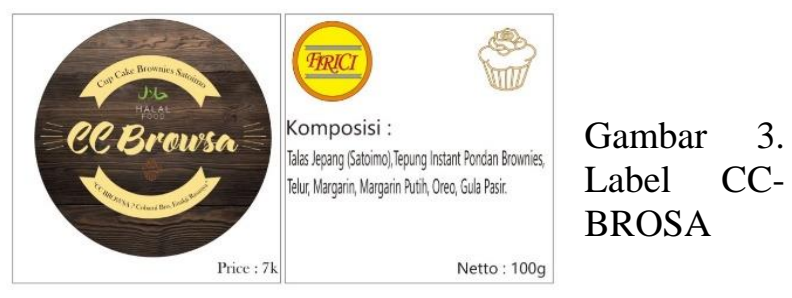

Tabel 1. Alat dan Bahan Produk CC-BROWSA

\begin{tabular}{|c|c|c|}
\hline NO. & $\begin{array}{c}\text { JENIS ALAT } \\
\text { DAN BAHAN }\end{array}$ & $\begin{array}{c}\text { JUMLAH } \\
\text { KEBUTUHAN (UNIT) }\end{array}$ \\
\hline 1. & Talas Jepang & 16 buah $(200 \mathrm{~g})$ \\
\hline 2. & $\begin{array}{c}\text { Tepung Instant } \\
\text { Pondan Brownies }\end{array}$ & 1 bungkus \\
\hline 3. & Telur & 6 butir \\
\hline 4. & Margarin & 3 sendok makan \\
\hline 5. & $\begin{array}{c}\text { Margarin putih } \\
\text { (Topping) }\end{array}$ & $1 / 2 \mathrm{~kg}$ \\
\hline 6. & Oreo (Topping) & 48 butir \\
\hline 7. & $\begin{array}{c}\text { Gula Pasir } \\
\text { (Topping) }\end{array}$ & 2 sendok makan \\
\hline
\end{tabular}

\section{METODE}


Pada dasarnya metode yang digunakan dalam pengabdian ini adalah metode evaluasi dengan tiga tahap. Tahap pertama adalah membangun organisasinya berupa perusahaan kecil berbentuk CV untuk mewadahi kegiatan (aspek organisasi). Kedua, melakukan percobaan atau pengujian teknis produksi untuk memastikan kemampuan teknologi produksi menghasilkan produk layak konsumsi (aspek teknis); dan ketiga, melakukan evaluasi kelayakan investasi usaha untuk memastikan sustainability usaha (aspek keuangan). Khusus tahap tiga dititik-beratkan pada proyeksi Rugi-Laba.

\section{HASIL DAN PEMBAHASAN}

Aspek Administrasi. Dua hal yang paling utama; yakni terbentuknya organisasi SDM dan penunjangnya untuk menjalankan fungsi manjemen, dan diperolehnya perizinan agar memenuhi syarat konstitusional untuk beroperasi. Susunan manajmen CV BROSA terdiri atas Mnajer: Cindy Fatika, Manajer Keuangan Rima dan manajer produksi Fiqry. Sedan anggara perizinan dan administrasi lainnya diperlihatkan pada Tabel 1 .

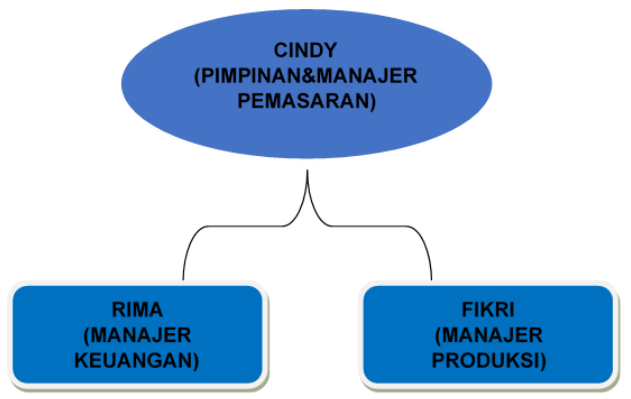

Tabel 1. Anggaran Biaya yang Dikeluarkan Untuk Alokasi Biaya Perizinan

\begin{tabular}{|c|c|c|c|c|c|c|}
\hline \multirow[b]{2}{*}{$\begin{array}{l}\mathrm{N} \\
\mathrm{o}\end{array}$} & \multirow[b]{2}{*}{$\begin{array}{c}\text { Jenis } \\
\text { Perizinan }\end{array}$} & \multirow[b]{2}{*}{$\begin{array}{l}\text { Instansi } \\
\text { Yang } \\
\text { Mengel } \\
\text { uarkan }\end{array}$} & \multirow{2}{*}{$\begin{array}{c}\text { Masa } \\
\text { Berla } \\
\text { ku } \\
\text { (tahu } \\
\text { n) }\end{array}$} & \multicolumn{3}{|c|}{ Biaya Perizinan (Rp) } \\
\hline & & & & $\begin{array}{c}\text { Poko } \\
\text { k } \\
(\mathrm{Rp})\end{array}$ & $\begin{array}{c}\text { Peng } \\
\text { uru- } \\
\text { san } \\
\text { (Rp) }\end{array}$ & $\begin{array}{l}\text { Jumla } \\
\text { h (Rp) }\end{array}$ \\
\hline 1 & 2 & 3 & 4 & 5 & 6 & 7 \\
\hline 1 & $\begin{array}{c}\text { Surat Izin } \\
\text { Tempat } \\
\text { Usaha }\end{array}$ & $\begin{array}{c}\text { Dinas } \\
\text { Perdaga } \\
\text { ngan }\end{array}$ & $\begin{array}{c}3 \\
\text { tahun }\end{array}$ & $\begin{array}{c}360.0 \\
00\end{array}$ & $\begin{array}{c}50.00 \\
0\end{array}$ & $\begin{array}{c}410.00 \\
0\end{array}$ \\
\hline $\begin{array}{l}2 \\
.\end{array}$ & $\begin{array}{c}\text { Surat Izin } \\
\text { Usaha } \\
\text { Perdaganga } \\
n\end{array}$ & $\begin{array}{c}\text { Dinas } \\
\text { Perdaga } \\
\text { ngan }\end{array}$ & $\begin{array}{c}5 \\
\text { tahun }\end{array}$ & 1.500 & $\begin{array}{c}30.00 \\
0\end{array}$ & $\begin{array}{c}1.530 . \\
000\end{array}$ \\
\hline
\end{tabular}

\begin{tabular}{|c|c|c|c|c|c|c|}
\hline 3 & $\begin{array}{c}\text { Surat } \\
\text { Tanda } \\
\text { Daftar } \\
\text { Perusahaan }\end{array}$ & $\begin{array}{l}\text { Dinas } \\
\text { Perindu } \\
\text { strian }\end{array}$ & $\begin{array}{c}5 \\
\text { tahun }\end{array}$ & $\begin{array}{c}350.0 \\
00\end{array}$ & $\begin{array}{c}30.00 \\
0\end{array}$ & $\begin{array}{c}380.00 \\
0\end{array}$ \\
\hline 4 & $\begin{array}{l}\text { Surat Izin } \\
\text { Dinas } \\
\text { Kesehatan }\end{array}$ & $\begin{array}{c}\text { Dinas } \\
\text { Kesehat } \\
\text { an }\end{array}$ & $\begin{array}{c}5 \\
\text { tahun }\end{array}$ & $\begin{array}{c}900.0 \\
00\end{array}$ & $\begin{array}{c}30.00 \\
0\end{array}$ & $\begin{array}{c}930.00 \\
0\end{array}$ \\
\hline 5 & $\begin{array}{c}\text { Surat Izin } \\
\text { Halal } \\
\text { Nomor }\end{array}$ & $\begin{array}{l}\text { MUI } \\
\text { Kantor }\end{array}$ & $\begin{array}{c}2 \\
\text { tahun }\end{array}$ & $\begin{array}{c}500.0 \\
00\end{array}$ & $\begin{array}{c}30.00 \\
0\end{array}$ & $\begin{array}{c}530.00 \\
0\end{array}$ \\
\hline 6 & $\begin{array}{l}\text { Pokok } \\
\text { Wajib } \\
\text { Pajak }\end{array}$ & $\begin{array}{c}\text { Pelayan } \\
\text { an } \\
\text { Pajak }\end{array}$ & - & - & $\begin{array}{c}25.00 \\
0\end{array}$ & 25.000 \\
\hline 7 & $\begin{array}{l}\text { Surat Izin } \\
\text { Gangguan }\end{array}$ & $\begin{array}{c}\text { Polres } \\
\text { Makass } \\
\text { ar } \\
\end{array}$ & $\begin{array}{c}1 \\
\text { tahun }\end{array}$ & $\begin{array}{c}200.0 \\
00\end{array}$ & $\begin{array}{c}30.00 \\
0\end{array}$ & $\begin{array}{c}230.00 \\
0\end{array}$ \\
\hline & & & & & Total & $\begin{array}{r}4.035 \\
.000\end{array}$ \\
\hline
\end{tabular}

Aspek pasar dan pemasaran. Lokasi pemasaran difokuskan pada Kawasan Tamalanrea dengan pertimbangan dekat dari tempat produksi dan sebagai pintu gerbang Kota Makassar dari arah utara. Jumlah unt penjualan adalah kl 450 unit per bulan. Untuk hal pemasaran ini, terdapat tiga kompetitor existing di Kawasan ini: Brownies Amanda dengan permintaan 600 unit BoluTa 500 unit, dan Browcyl 500 unit per bulan (asil survei). Denga demikian posisi pasar (market share) produk CC-BROSA adalah sekitar $22 \%$ dari total permintaan.

Aspek Produksi. Produksi tidak hanya menciptakan produk sebagai keluaran (output), namun juga menggunakan berbagai faktor produksi sebagai masukan (input). Sebagaimana yang dikemukakan oleh Prawirosentono (1997) bahwa produksi adalah membuat atau menghasilkan produksi suatu barang dari berbagai bahan lain. Produksi sebagai suatu proses, diartikan sebagai cara, metode ataupun teknik bagaimana produksi itu dilaksanakan atau suatu kegiatan untuk menciptakan dan menambah kegunaan (utility) suatu barang dan jasa. Proses produksi dalam konteks kewirausahaan adalah merupakan kegiatan untuk menciptakan atau menambah kegunaan suatu barang atau jasa dengan menggunakan faktor-faktor produksi seperti tenaga kerja, mesin, bahan baku dan dana, agar menghasilkan produk yang dibutuhkan dan sesuai dengan yang diharapkan oleh konsumen (Rukka, 2011). Selain teknologi dan SDM maka hal yang sangat penting terkait produksi adalah ketersediaan 
bahan baku. Bahn baku dan harganya diperlihatkan pada Tabel 2. Peralatan pada Tabel 3

Tabel 3. Bahan Baku Produksi CC BROWSA

\begin{tabular}{|c|c|c|c|c|c|}
\hline $\begin{array}{l}\mathbf{N} \\
\mathbf{o}\end{array}$ & $\begin{array}{l}\text { Jenis } \\
\text { Bahan }\end{array}$ & $\begin{array}{c}\text { Jumlah } \\
\text { Kebutuha } \\
\text { n (unit) }\end{array}$ & $\begin{array}{r}\text { Harga } \\
\text { Satuan } \\
\text { (Rp/unit }\end{array}$ & $\begin{array}{c}\text { Jumlah } \\
\text { Biaya } \\
\text { (Rp) }\end{array}$ & $\begin{array}{l}\text { Sumber } \\
\text { Pasokan }\end{array}$ \\
\hline $\mathbf{I}$ & \multicolumn{5}{|c|}{ BAHAN LANGSUNG } \\
\hline 1 & Satoimo & 16 buah & 600 & 9.600 & $\begin{array}{l}\text { Pt. } \\
\text { Satoimo } \\
\text { Sulawesi } \\
\text { Sukses }\end{array}$ \\
\hline 2 & $\begin{array}{l}\text { Tepung } \\
\text { Instant } \\
\text { Pondan }\end{array}$ & 1 bungkus & 27.000 & 27.000 & Indomaret \\
\hline 3 & Telur & $\begin{array}{l}6 \text { butir } \\
3 \text { sachet }\end{array}$ & 1.700 & 10.200 & Toko Kue \\
\hline 4 & Margarin & $\begin{array}{ll}(@ & 17 \\
\text { gram }) & \end{array}$ & 1.000 & 3.000 & Toko Kue \\
\hline 5 & $\begin{array}{l}\text { Margarin } \\
\text { Putih }\end{array}$ & $1 / 2 \mathrm{~kg}$ & 10.000 & 5.000 & Toko Kue \\
\hline 6. & Gula Pasir & $\begin{array}{l}\text { Secukupny } \\
\text { a }\end{array}$ & 1.000 & 1.000 & Toko Kue \\
\hline 7. & Oreo & 1 cup & 8.000 & 8.000 & Indomaret \\
\hline \multicolumn{4}{|c|}{ Sub-Total Biaya Bahan Langsung } & 63.800 & \\
\hline II & \multicolumn{4}{|c|}{ BAHAN TIDAK LANGSUNG } & \\
\hline 1. & Kompor & 1 buah & 250.000 & 250.000 & $\begin{array}{l}\text { Toko } \\
\text { Elektronik }\end{array}$ \\
\hline 2. & $\begin{array}{l}\text { Tabung } \\
\text { Gas+Isi }\end{array}$ & 1 buah & 150.000 & 150.000 & $\begin{array}{l}\text { Toko } \\
\text { Online }\end{array}$ \\
\hline 3. & Mixer & 1 buah & 130.000 & 130.000 & $\begin{array}{l}\text { Toko } \\
\text { Online }\end{array}$ \\
\hline 4. & Oven & 1 buah & 300.000 & 300.000 & $\begin{array}{l}\text { Toko } \\
\text { Online }\end{array}$ \\
\hline 4. & Kemasan & 24 buah & 1.500 & 36.000 & Toko Kue \\
\hline \multicolumn{4}{|c|}{$\begin{array}{c}\text { Sub-Total Biaya Bahan Tidak Langsung } \\
\text { TOTAL BIAYA PENG. BAHAN }\end{array}$} & $\begin{array}{l}566.000 \\
629.800 \\
\end{array}$ & \\
\hline
\end{tabular}

Aspek Keuangan. Kebutuhan keuangan meliputi kebutuhan awal yang meliputi modal investasi dan modal kerja. Modal ini bisa berupa uang dan tenaga (keahlian). Modal uang biasa digunakan untuk membiayai berbagai keperluan usaha, seperti biaya prainvestasi, pengurusan izin, biaya investasi untuk membeli aset, hingga modal kerja. Sedangkan modal keahlian adalah kepiawaian seseorang dalam menjalankan suatu usaha (Darsono, 2005).

Menurut Rukka (2011), modal yang digunakan dalam menjalankan perusahaan terdiri dari modal investasi dan modal kerja. Berikut ini memperlihatkan komposisi modal (Tabel 4)

Berikut ini adalah sumber modal dari usaha Brownies Satoimo (Tabel 5)
Tabel 4. Sumber Modal Usaha Brownies Satoimo

\begin{tabular}{|c|c|c|c|c|c|}
\hline \multirow{2}{*}{$\begin{array}{c}\text { N } \\
\mathbf{0}\end{array}$} & $\begin{array}{c}\text { Jenis } \\
\text { Modal }\end{array}$ & $\begin{array}{c}\text { Sendiri } \\
\text { (Rp) }\end{array}$ & $\begin{array}{c}\text { Pinja } \\
\text { man } \\
\text { (Rp) }\end{array}$ & $\mathbf{( R p )}$ & $\mathbf{( \% )}$ \\
\hline 1 & $\begin{array}{c}\text { Modal } \\
\text { Investasi }\end{array}$ & 63.800 & 0 & 63.800 & 6,86 \\
\hline 2 & $\begin{array}{c}\text { Modal } \\
\text { Kerja }\end{array}$ & 866.000 & 0 & 866.000 & 93,14 \\
\hline \multicolumn{2}{|c|}{ Total } & 929.800 & - & 929.800 & \multicolumn{2}{|c|}{ Total } \\
\hline
\end{tabular}

\section{Proyeksi Neraca.}

Neraca adalah sebuah laporan tentang posisi keuangan perubahan pada suatu titik waktu tertentu. Menurut Imam Santoso neraca adalah suatu laporan yang menginformasikan mengenai aktiva, kewajiban dan kepemilikan (ekuitas) suatu perusahaan pada waktu tertentu. Dimana neraca menunjukkan posisi keuangan Perusahaan pada saat tanggal tertentu, biasanaya pada waktu dimana buku-buku ditutup dan ditemukan sisanya pada suat akhir bulan fiscal atau kalender, sehingga neraca sering disebut dengan balance sheet (Sangkala, 2009).

Laporan neraca adalah laporan yang menunjukkan posisi keuangan perusahaan pada tanggal tertentu.Posisi keuangan yang dimaksud adalah posisi aktiva (harta lancar), passiva (kewajiban), dan ekuitas (modal) suatu perusahaan.Penyusunan komponen di dalam neraca biasanya didasarkan pada tingkat likuiditas dan jatuh temponya (Kasmir, 2010).

Harta lancar adalah harta yang diharapkan dapat diubah menjadi uang tunai dalam masa 12 bulan selama perjalanan normal bisnis; biasanya mencakup uang tunai, piutang, sediaan, dan biaya yang dibayar dimuka. Harta tetap adalah harta yang tidak akan diubah menjadi uang tunai; biasanya mencakup tanah, gedung, dan peralatan (Kasmir, 2010).

Kewajiban (utang) mencakup semua yang diutang oleh perusahaan dari pihak lain. Utang lancar mencakup hutang yang diharap untuk dibayar dalam 12 bulan, seperti pinjaman jangka pendek dari bank. Utang jangka panjang mencakup pinjaman jangka panjang atau yang lebih lama dari satu tahun. Ekuitas mencakup dana yang dibayarkan kepada

Ekonomi, Sosial dan Budaya

1011 
perusahaan oleh para pemegang saham ditukar dengan saham (Kasmir, 2010).

Modal merupakan hak atau bagian yang dimiliki oleh pihak perusahaan ditunjukkan dalam pos modal atau modal saham, surplus dan laba yang ditahan. Atau kelebihan nilai aktiva yang dimiliki oleh perushaan terhadap seluruh hutang-hutangnya (Sangkala, 2009).

Berikut ini adalah proyeksi neraca usaha Brownies Satoimo untuk tahun pertama:

Tabel 5. Proyeksi Neraca Usaha Brownies Satoimo

\begin{tabular}{|c|c|c|}
\hline No. & Uraian & $\begin{array}{c}\text { Tahun } \\
\text { pertama } \\
(\mathrm{Rp})\end{array}$ \\
\hline A. & AKTIVA & \\
\hline I. & Aktiva Lancar & \\
\hline a. & Kas & 929.800 \\
\hline b. & Persediaan Keperluan Toko & 0 \\
\hline c. & $\begin{array}{l}\text { Persediaan Keperluan } \\
\text { Kantor }\end{array}$ & 175.000 \\
\hline \multicolumn{2}{|r|}{ Total Aktiva Lancar } & 1.104.800 \\
\hline II. & Aktiva Tetap & \\
\hline a. & Peralatan & 866.000 \\
\hline \multicolumn{2}{|r|}{ Total Aktiva Tetap } & 866.000 \\
\hline \multicolumn{2}{|r|}{ Total Aktiva (I+II) } & 1.970 .800 \\
\hline B. & PASSIVA & \\
\hline I. & Utang Jangka Pendek & \\
\hline a. & Wesel Bayar & 0 \\
\hline b. & Utang Dagang & 0 \\
\hline c. & Kredit Modal Kerja & 0 \\
\hline d. & Penerimaan di Muka & 0 \\
\hline \multicolumn{2}{|r|}{ Total Utang Jangka Pendek } & 0 \\
\hline II. & Utang Jangka Panjang & \\
\hline a. & Obligasi & 0 \\
\hline b. & Kredit Investasi & 0 \\
\hline c. & Kredit Hipotek & 0 \\
\hline \multicolumn{2}{|r|}{ Total Utang Jangka Panjang } & 0 \\
\hline
\end{tabular}

\begin{tabular}{|r|r|r|}
\hline III. & Modal Sendiri & \\
\hline \multicolumn{2}{|c|}{ Total Passiva (I+II+III) } & $\mathbf{9 2 9 . 8 0 0}$ \\
\hline
\end{tabular}

Pada akhirnya analisis Rugi-Laba yang paling menentukan kelayakan usaha yang dapat dilanjutkan. CC-BROSA dinyatakan layak untuk dilanjutkan terutama disebabkan oleh kriteriakriteria investasi yang menyatakan potensi keuntungan.

\section{Proyeksi Rugi-Laba}

Laporan yang mengiktisarkan pendapatan dan pengeluaran perusahaan selama satu periode akuntansi, yang biasanya selama satu kuartal atau satu tahun. Laporan laba rugi merupakan laporan yang

sistematis tentang penghasilan, biaya laba rugi yang diperoleh suatu usaha selama periode tertentu (Brigham dan Houston, 2006).

Peningkatan laba perusahaan CV. FIRICI GROUP selama 5 tahun dapat dilihat pada tabel 25 di bawah ini:

Tabel 6. Proyeksi Rugi-Laba

\begin{tabular}{|c|c|c|}
\hline No. & Uraian & $\begin{array}{c}\text { Tahun } \\
\text { Pertama (Rp) }\end{array}$ \\
\hline \multirow[t]{3}{*}{ I. } & Hasil Penjualan & 37.800 .000 \\
\hline & (-) Potongan Penjualan & 378.000 \\
\hline & (-) Pengembalian & 0 \\
\hline 2. & Total Penjualan Bersih & 37.422 .000 \\
\hline 3. & Harga Pokok Penjualan & \\
\hline a. & $\begin{array}{l}\text { Persediaan Awal Barang Jadi } \\
\text { (per } 1 \text { Januari tahun berjalan) }\end{array}$ & 1.196 .250 \\
\hline \multirow[t]{5}{*}{ b. } & Harga Pokok & \\
\hline & - Bahan & 63.800 \\
\hline & - Upah & 6.000 .000 \\
\hline & - Biaya Umum Pabrik & 0 \\
\hline & - Penyusutan Peralatan & 72.000 \\
\hline c. & $\begin{array}{l}\text { Barang Jadi yang Tersedia } \\
(a+b)\end{array}$ & 7. 332.050 \\
\hline d. & $\begin{array}{l}\text { Perlengkapan } \\
\text { (per } 1 \text { Desember tahun } \\
\text { berjalan) }\end{array}$ & 866.000 \\
\hline 4. & Total Harga Pokok Penjualan & 6.466 .050 \\
\hline 5. & Laba Kotor (2-4) & 30.955 .950 \\
\hline \multirow[t]{2}{*}{6.} & Biaya & \\
\hline & Operasional/Administrasi & \\
\hline \multirow[t]{2}{*}{ e. } & Gaji Tenaga Kerja & 2.000 .000 \\
\hline & Ekonomi, Sosial dan Budaya & 1012 \\
\hline
\end{tabular}




\begin{tabular}{llr} 
f. & $\begin{array}{l}\text { Biaya Pemasaran } \\
\text { g. }\end{array}$ & $\begin{array}{l}\text { Biaya Administrasi dan } \\
\text { Umum }\end{array}$ \\
7. & $\begin{array}{l}\text { Total Biaya } \\
\text { Operasional/Administrasi }\end{array}$ & 4.140 .000 \\
& $\begin{array}{l}\text { (e+f+g) } \\
\text { 8. }\end{array}$ & 12.373 .000 \\
& Laba Usaha/Operasional (5- & 18.582 .950 \\
9. & Kewajiban Terhadap Bank & \\
h. & Angsuran & 0 \\
i. & Bunga & 0 \\
10. & Total Kewajiban Terhadap & 0 \\
& Bank (h+i) & \\
11. & Laba Sebelum Pajak (8-10) & 18.582 .950 \\
12. & Pajak (10\%) & 1.858 .295 \\
\hline 13. & Laba Bersih (11-12) & 16.724 .655 \\
\hline & & \\
\hline
\end{tabular}

\section{KESIMPULAN}

Setiap bulan kami menargetkan minimal 450 box yang terjual, dan kami juga menargetkan minimal 5400 unit. Data ini kami dapatkan berdasarkan perhitungan yang kami lakukan, agar perputaran uang dalam perusahaan berjalan dengan baik. Rencana pendapatan perusahaan perusahaan perbulan jika produk kami terjual sebanyak target minimal yaitu 450 box dengan harga jual sebesar Rp. 7.000/box, maka kami mendapatkan minimal hasil penjualan sebesar Rp. 3.150.000/bulan. Modal awal yang kami dapatkan dari uang pribadi masingmasing yaitu sebesar Rp. 929.000. Perusahaan prastart-up produsen CC-BROSA dinatakan layak untuk dikembangkan

\section{REFERENSI}

Adams, Sean. \& Morioka, Noreen. (2004). Logo Design Workbook. Massachusetts: Rockport Publishers

Adiwijaya M. (2008). Perluasan Merek:"Strategi Jitu Peluncuran Produk Baru". Surabaya: Universitas Kristen Petra.

Agung, Fitra Batara Dan Zirman (2011). Pengaruh Rasio Keuangan Terhadap Perubahan Laba (Studi Pada Perusahaan Industri \& Chemical Yang Terdaftar Di Bursa Efek Indonesia 20072010). Jurnal Universitas Riau.

Athoillah, A. (2010). Dasar-Dasar Manajemen. Bandung: Pustaka Setia
Bahtiar Usman (2003). Analisis Rasio Keuangan Dalam Memprediksi Perubahan Laba Pada Bank-Bank Di Indonesia. Media Riset Bisnis Dan Manajemen.Vol.3. No.1. April.2003. Pp.59-74.

Bradbury, J.H. Dan Holloway, W.D. (1988). Chemistry of Trofical Root Crops: Significance For Nutrition And Agriculture In The Pacific. Australian National Univ Pr, Canberra.

Brigham dan Houston (2006). Fundamental of Financial Management. Jakarta: Salemba Empat. Hml., 50.

Darsono (2005). Pedoman Praktis Memahami Laporan Keuangan. Salemba Empat. Jakarta.

Dedes A. (2012). Kualitas Daging Sapi Segar Di Pasar Tradisional Kecamatan Poncokusumo Kabupaten Malang. Jurnal Ilmu Dan Teknologi Hasil Ternak, , Hal 42-47 Vol. 7, No. 1. Universtitas Brawijaya.

Dewi A.W. (2010). Teori Dan Pengukuran Pengetahuan dan Sikap Dan Perilaku Manusia. Yogyakarta: Nuha Medika.

Iwuoha, I. Chinyere And F. A. Kalu. (1995). Calcium Oxalate Dan Physico-Chemical Propertise Of Cocoyam (Colocasia Esculanta And Xanthosoma Sagittifolium) Tuber Flours as Affected by Processing. J. Food Chem. 54:6166.

Jennie B.S.L. Dan W.P. Rahayu (1993). Penanganan Limbah Industri Pangan. Yogyakarta:Kanisius

Kasmir (2010). Kewirausahaan. Jakarta: PT. Raja Grafindo Persada

Kementrian Perdagangan RI (2013). Menuju Asean Economic Community 2015. Direktur Jendral Perdagangan Internasional. Jakarta.

Kotler, Philip (2001). Manajemen Pemasaran di Indonesia. Jakarta: Salemba

Kurniawan, Anggoro Dwi Dan Sri Rahayu Tri Astuti (2012). Analisis Pengaruh Produk, Promosi, Harga Dan Tempat Terhadap Keputusan Pembelian (Studi Pada Kedai Amarta Semarang). Diponegoro Journal Of Management. Vol.1, No.1, Hal 282-289.

Lee, W. 1999. Taro. Di Dalam Heidegger, A. (Ed) (1999). Tropical Root Crops. Southern Illinois University, Illionis. 
Moriarty, Sandra., Mitchell, Nancy., \& Wells, William (2011). Advertising: Edisi Kedelapan. Jakarta: Kencana

Nur, M. (1986). Tanaman Talas (Colocasia Dan Beberapa Genus Yang Lain). Kementrian Pertanian, Jakarta.

Orismawanti D Dan Lukman H. 2014. Analisis Proyeksi Arus Kas Untuk Menentukan Hasil Dalam Penilaian Keputusan Kelayakan Investasi. Bogor: Sekolah Tinggi Ilmu Ekonomi Kesatuan.

Prawirosentono S. 1997. Kebijakan Kinerja Karyawan. Yogyakarta: Bpfe

Rukka R.M. 2011. Buku Ajar Kewirausahaan-1. Makassar: Unhas.

Sangkala, Abd. Azis, ”Analisis Kinerja Keungan Berdasarkan Rasio Porfitabilitas Pada Perusahaan Pabrik Roti Tony Bakery Pare Pare," Jurnal Ekonomi (Makasar:Unismuh Makasar,2009)

Santoso, Slamet (2013). Stasistika Ekonomi Plus Aplikasi SPSS, Ponorogo: Umpo Press.

Smith, D.S. (1997). Processing Vegetabkes Science And Technology. Technonic Pubishing Company Inc., London.

Subagio A. (2007). Industrialisasi Modified Cassava Flour (Mocaf) Sebagai Bahan Baku Industri Pangan Untuk Menunjang Diversifikasi Pangan Pokok Nasional. Jember: Fakultas Teknologi Pertanian, Universitas Jember.

Suharyadi (2010). Interpretasi Hibrida Citra Satelit Resolusi Spasial Menengah Untuk Kajian Densifikasi Bangunan Perkotaan di Daerah Perkotaan Yogyakarta. Ringkasan Disertasi. Yogyakarta: Fakultas Geografi Universitas Gadjah Mada.

Suyanto Danang (2012). Prosedur Uji Hipotesis Untuk Riset Ekonomi, Yogyakarta: Alfabeta.

Tjiptono Fandy (2002). Strategi Pemasaran. Yogyakarta: Penerbit Andi 